\title{
赤外一可視変換蛍光体 $(\mathrm{Y}, \mathrm{Yb}, \mathrm{Er}) \mathrm{F}_{3}$ のフラックス焼成における 2 段焼成亡酸エッチングの結晶成長に及ぼす効果
}

\author{
平 野 正 夫*, 竹 内 信 義 \\ Effects of 2 Step-Firing and Acid Etching on the Crystal Growth in Firing an \\ Infrared-to-Visible Conversion Phosphor $(\mathrm{Y}, \mathrm{Yb}, \mathrm{Er}) \mathrm{F}_{3}$ with Flux
}

\author{
Masao HIRANO* and Nobuyoshi TAKEUCHI ${ }^{\dagger}$
}

Received May 7, 1986; Accepted September 4, 1986

\begin{abstract}
1 緒言
赤外 - 可視変換蛍光体 (以下 IRV 蛍光体上略す)は， 半導体光源なよ゙の強い赤外線励起によって可視発光を生 じ, ( Y,Yb,Er) F $\mathrm{F}_{3}$ はその代表例である.

蛍光体のフォトルミネッセンスをレーザ光の検出 ${ }^{1)}$, 光コード読取 ${ }^{21}$, 温度計湘 ${ }^{33}$ などの光計測に利用するこ とが提案されている.IRV 営光体をそれらの目的に適用 すれば，光源に発光ダイオードを用いるここができるの で，計測系が簡単になり，計測制御も容易になる。

一方, IRV 蛍光体は発光効率が低いことが課題である ので, 本研究は光計测に適した高発光効率のIRV 蛍光 体を実現するため, ( $\mathrm{Y}, \mathrm{Yb}, \mathrm{Er}$ ) $\mathrm{F}_{3}$ のフラックス焼成法 の検討を行った.
\end{abstract}

\section{1 蛍光体の合成 \\ 2 実験}

(Y,Yb,Er) $F_{3}$ の合成には，湿式を用いた. Fig.1に 合成の標準プロセスを示す。まず，出発物質の希土酸化 物 $\mathrm{Y}_{2} \mathrm{O}_{3}, \mathrm{Yb}_{2} \mathrm{O}_{3}, \mathrm{Er}_{2} \mathrm{O}_{3}$ (信越化学製, 純度 99.99 以上) を硝酸に溶解し, フッ化水素酸を徐々に滴下して YF $\mathrm{YbF}_{3}, \mathrm{ErF}_{3}$ の半水和物を共沈させた。この沈測を 100 〜 $105^{\circ} \mathrm{C}$ で蒸発乾固した後, 高純度アルミナるつぼに上 り,フッ化物フラックス $\mathrm{ZnF}_{2} \cdot 4 \mathrm{H}_{2} \mathrm{O}$ (森田化学工 業製）を $30 \mathrm{wt} \%$ 加えて焼成した，焼成は環状炉を用 い,Arガスふん囲気で行った，焼成温度は，予備実験

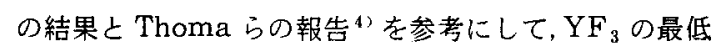
転移点 $1029 \pm 6{ }^{\circ} \mathrm{C}$ の方の $1000^{\circ} \mathrm{C}$ に設定した。焼成プ ロファイルは，徐熱一焼成一急冷を行った，合成実験の

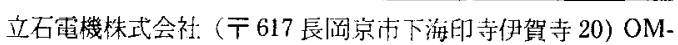
RON TATEISI ELECTRONICS CO. (Shimokainji, Nagaokakyo, Kyoto, 617)

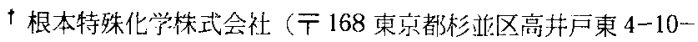
9) NEMOTO \& CO., LTD. (4-10-9, Takaidohigashi, Suginami, Tokyo, 168)

KeyWords : Phosphor, Infrared Excitation, StepwiseFiring, Maturing

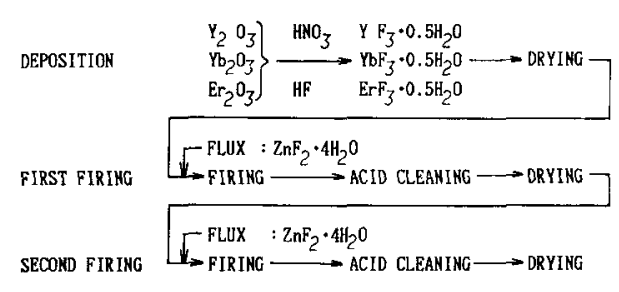

Fig.1 Standard synthetic process of $(\mathrm{Y}, \mathrm{Yb}, \mathrm{Er}) \mathrm{F}_{3}$

各条件を Table 1 に示す。 また, 湿式法之乾式法の比 較も行った。

\section{2 発光強度の測定}

栄光スペクトルは, 蛍光分光光度計（島津製作所製, RF 502 型）を用い，励起分光器で生じる赤外励起光の 2 次光をハイパス・フィルタ R 68 でしゃ断して測定し た. 蛍光スペクトルの面積を反射発光強度と定義した。

また, IRV 蛍光体を透明シリコン樹脂（信越シリコー ン KJR 9023)に50 wt\% 分散させたペレットを作製 し, 発光ダイオードーペレットーGaAsP フォトダイ オードの構成で透過発光強度を測定した. 発光ダイオー ドには, $\mathrm{GaAs}: \mathrm{Si}$ (立石電機製, $\lambda_{\mathrm{P}}=940 \mathrm{~nm}$ ) を用い, 順方向電流 $I_{\mathrm{F}}=100 \mathrm{~mA}$ で測定した。

\section{3 粒子径の測定, 粒子形状, 粒子表面の観察}

蛍光体の粒子径の測定，粒子形状，粒子表面の観察に は, 電子顕微鏡（明石製作所製, Mini SEM 6) を用い た.

\section{$2.4 \mathrm{X}$ 線回析测定}

蛍光体の結晶構造の同定上結晶性評価には, $\mathrm{X}$ 線回析 装置（理学電機製, Geiger flex No.2027）を用いた. 試 料が大粒径であるため, 通常は粉砕して供試した。

\section{5 粒子内面の結晶性評価}

as grown 粒子の表面を, 1 2 $\mu \mathrm{m}$ ずつ皮をはがす要 領で，一定時間ずつ濃硫酸でエッチングを行い，粒子の 深さ方向の結晶性の変化を調べた，結晶性は, 反射発光 強度と X 線回析強度を測定して評価した. X 線回析は, 
Table 1 Synthetic processes of $(\mathrm{Y}, \mathrm{Yb}, \mathrm{Er}) \mathrm{F}_{3}$ and results

\begin{tabular}{|c|c|c|}
\hline sample & synthetic process & $\begin{array}{l}\text { relative } \\
\text { reflective } \\
\text { emission } \\
\text { intensity }\end{array}$ \\
\hline $21-1$ & standard process as shown Fig.1 & 100 \\
\hline $21-2$ & dry process of synthesizing $(\mathrm{Y}, \mathrm{Yb}, \mathrm{Er}) \mathrm{F}_{3}: 1$ time, firing: 2 times & 19 \\
\hline $21-3$ & dry process of synthesizing $(\mathrm{Y}, \mathrm{Yb}, \mathrm{Er}) \mathrm{F}_{3}: 2$ times, firing: 2 times & 20 \\
\hline $4-1$ & standard process as shown Fig.1 & 100 \\
\hline $4-2$ & deposition was added with flux when 2 nd fired & 45 \\
\hline $4-3$ & 3 rd firing by standard process & 96 \\
\hline $4-4$ & acid cleaning + conc. $\mathrm{H}_{2} \mathrm{SO}_{4}$ etching at room temp. after 1 st and 2 nd firing & 104 \\
\hline $4-5$ & acid cleaning + conc. $\mathrm{H}_{2} \mathrm{SO}_{4}$ etching at $70^{\circ} \mathrm{C}$ after lst and 2 nd firing & 109 \\
\hline $5-1$ & standard process as shown Fig.1 & 100 \\
\hline $5-3$ & continuous firing $1000^{\circ} \mathrm{C}-180 \mathrm{~min}: 1$ time & 94 \\
\hline
\end{tabular}

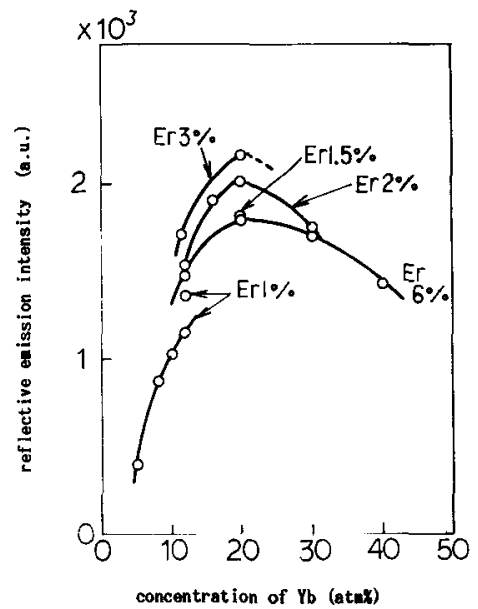

Fig. 2 ariation of reflective emission intensity with $\mathrm{Yb}^{3+}$ concentration of $(\mathrm{Y}, \mathrm{Yb}, \mathrm{Er}) \mathrm{F}_{3}$

粒子表層の状態が反映するように，大粒径のまま测定し た.

\section{3 結果および考察}

\section{$3.1(\mathrm{Y}, \mathrm{Yb}, \mathrm{Er}) \mathrm{F}_{3}$ の最適粗成}

Fig.1に示す標準プロセスにより, $\mathrm{Yb} / \mathrm{Er}$ 濃度比を変 えた $(\mathrm{Y}, \mathrm{Yb}, \mathrm{Er}) \mathrm{F}_{3}$ 拿成し, 反射発光強度が最大に なる組成を調べた。得られた IRV 虽光体は，いずれも $\mathrm{Er}^{3+}$ ( ${ }^{4} \mathrm{~S}_{3 / 2} \rightarrow{ }^{4} \mathrm{I}_{15 / 2}$ 遷移に基づく緑色発光 $(547 \mathrm{~nm})$ を示す. Fig.2 はこの発光の Y b $/$ Er 濃度依存性を示し， 図から最適組成は $\mathrm{Y}_{0.77} \mathrm{Yb}_{0202} \mathrm{Er}_{003} \mathrm{~F}_{3}$ であることがわか る. 過去に $\mathrm{Y}_{0.80} \mathrm{Yb}_{0.19} \mathrm{Er}_{0.01} \mathrm{~F}_{3}$ が罗適組成であるという 報告例があるが5゙，焼成温度が $1100^{\circ} \mathrm{C}$ 上高いことや発 光强度評価法の差がその原因上考えられる，本実験で得

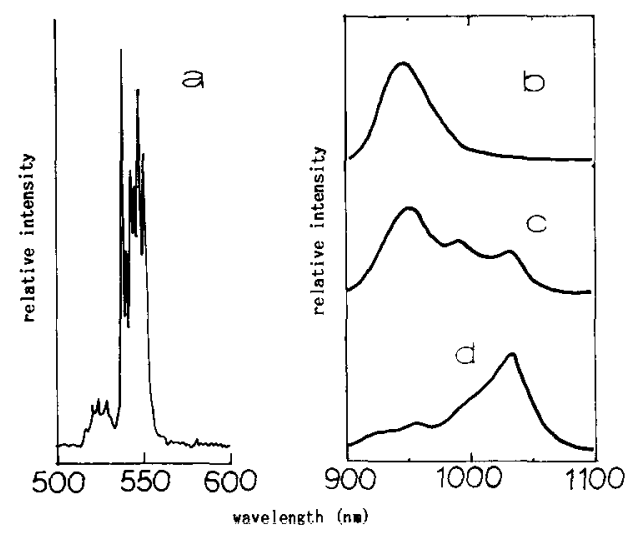

Fig. 3 Emission spectra of (Y,Yb,Er) $\mathrm{F}_{3}$ a: green emission spectra

b: excitation spectrum of GaAs: Si LED

c: infrared emission spectra of $990 \mathrm{~nm}$ and $1030 \mathrm{~nm}$ and excitation spectrum for thin phosphor layer

$\mathrm{d}$ : same as $\mathrm{c}$ but for thicker phosphor layer

られた発光体は，すべて orthorhombic の結晶構造を とり，Thoma らの報告にある希土フッ化物の相図

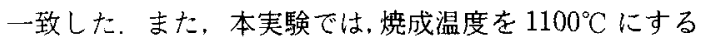
上, 発光強度が $1000^{\circ} \mathrm{C}$ 焼成の約 $50 \%$ に低下した。

\section{2 発光強度測定の留意点}

IRV 蛍光体の反射発光強度を測定する際に, 赤外励 起光に励起光器内で発生した 2 次光 $(488 \mathrm{~nm})$ を含む 上, 緑色発光が強められ, $\mathrm{Y}_{0.795} \mathrm{Yb}_{0.20} \mathrm{Er}_{0.015} \mathrm{~F}_{3}$ の組成 で最大になった。この現象は，GdF G $_{3}$ 体ではさらに著 しく現わ㣗，その原因は，現在のところ2 次光に上る增 感作用ではないか上考えている，通常，蛍光分光光度計 は赤外励起を考慮して設計されていないために生じる問 
Table 2 Variation of reflective emission intensity with perticle size

\begin{tabular}{|c|c|c|c|c|}
\hline \multirow{2}{*}{ measured parameter } & \multicolumn{3}{|c|}{ meshed sample } & \multirow{2}{*}{ total } \\
\hline & small & medium & large & \\
\hline particle size $\min .(\mu \mathrm{m})$ & 5 & 20 & 30 & \\
\hline typ. $(\mu \mathrm{m})$ & $10 \sim 20$ & $30-40$ & 60 & \\
\hline $\max .(\mu \mathrm{m})$ & 30 & 70 & 150 & \\
\hline content in as grown (wt\%) & 11.4 & 11.4 & 65.7 & $100^{*}$ \\
\hline reflective emission intensity (a.u.) & 98 & 103 & 138 & 100 \\
\hline transmissive emission int.(a.u.) & 86 & 104 & 123 & 100 \\
\hline
\end{tabular}

* Another $11.5 \%$ of as grown were lost when meshed
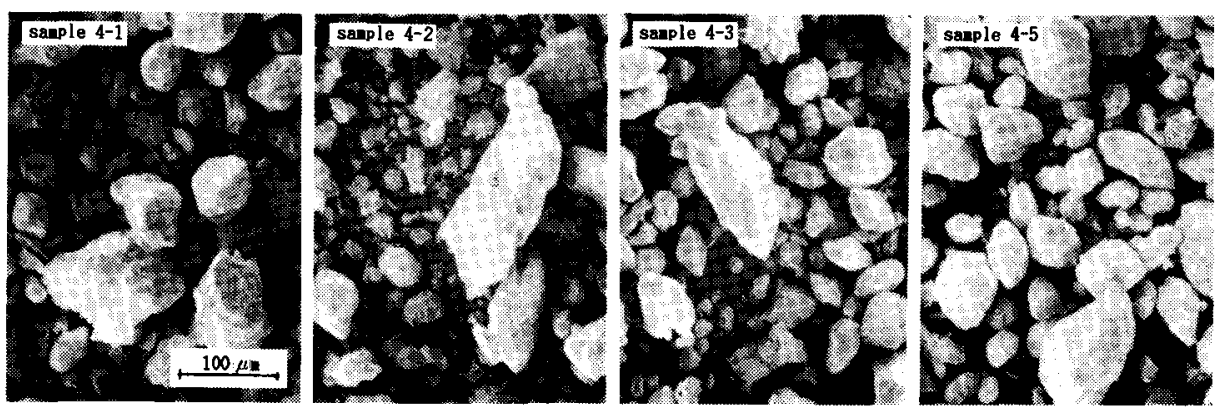

Fig. 4 SEM photoes of as grown samples

題である.

また，IRV 蛍光体は，Fig.3に示す上うに，緑色発光 の他に赤外励起波長付近に発光があり，その透過発光强 度が発光体層の厚さによって著しく变化するので，測定 には注意在要する。本実験の透過発光強度测定に $\mathrm{GaAsP}$ フォトダイオードを用いたのは，緑色光だけを 検知するためである。

\section{3 湿式法と乾式法の比較}

希土フッ化物の沈澱合成について湿式と乾式の比較を 行った，湿式は標隼プロセスを用い，乾式は下記のよう に反応させた。

$$
\begin{aligned}
\mathrm{Y}_{2} \mathrm{O}_{3}, & \mathrm{Yb}_{2} \mathrm{O}_{3}, \mathrm{Er}_{2} \mathrm{O}_{3} \\
& \stackrel{\mathrm{NH}_{4} \mathrm{~F}, 300^{\circ} \mathrm{C}-60 \mathrm{~min}}{\mathrm{Ar} \text { flow }}(\mathrm{Y}, \mathrm{Yb}, \mathrm{Er}) \mathrm{F}_{3}
\end{aligned}
$$

試料 21-2 は上記反広を 1 回，試料 21-3 は 2 回行い， 標準プロセスと同一条件で焼成した。乾式による試料は 反射発光強度が湿式の約 $20 \%$ しか得られなかった。 IRV 蛍光体のように高濃度に不純物をドープする場合， 湿式の方が均一な固溶状態が得られるため上考える。

\section{4 発光强度の粒子径依存性}

2 段焼成によって得ら机た粒子(以下 2 次粒子よいう) を沈降法で 3 段階に分級し，発光強度と粒子径の関係を 調べた. Table 2 に, 分級試料の粒子径の測定結果, 分
級の重量比, 反射発光強度, 透過発光強度などを比較し て示す，表から，粒子径が大きいほよ゙発光強度が大きい ことがわかる，とくに，反射測定における大粒径の発光 強度増加が著しい．大粒径(large) の分布は, as grown に対し $65.7 \%$ の重量比を占め，仕込みに対しては $45 \%$ の収率であった. 大粒径粒子が高い発光強度を示すのは, 結晶成長が良好であるためと粒子界面での散乱や反射が 少ないためであるう。

\section{5 大粒径粒子の成長過程の解析}

\section{（1）多段焼成の効果}

1 次粒子は大きいもので 30〜 40 $\mu \mathrm{m}$ に成長し, 2 次粒 子は最大 $150 \mu \mathrm{m}$ ぐらいまで成長する。この間に，発 光強度は明らかに増大する，そこで，さらに大きな粒子 を成長するため，標準プロセス 4-1の 2 次粒子に 3 次 焼成 $\left(1000^{\circ} \mathrm{C}-60 \mathrm{~min}\right)$ を行い試料 4-3 を得た. 3 次焼 成では，反射発光強度が 2 段焼成の $96 \%$ とわずかに低 下し，粒子径は成長しなかった. (Fig.4 参照)

\section{（2）焼成時間の影響}

標準プロセス $5-1$ Ł $1000^{\circ} \mathrm{C}-180 \mathrm{~min}$ 連続焼成試料 5-3 の反射発光強度を比較する上, $180 \mathrm{~min}$ 連続焼成の 方が標準プロセスよりも6\%小さく，長時間焼成しても ほとんよ゙効果がなく, むしろ発光強度が低下した。

（3）酸エッチングの効果 
3 段焼成を行っても粒成長が進まないことがわかった ので，粒成長が停止する原因を調べた. Fig.5 は2 次粒 子定時間ずつエッチングした後，平均粒子径，反射 発光強度, $X$ 線回析強度を測定した結果を示す。２次粒 子は表面から約 $1.5 \mu \mathrm{m}$ の深さで最大の発光強度とな り，X 線回析強度も同じ深さまで回析パターンが乱れて いる。ここ的の結果から,粒子表層に $2 \sim 3 \mu \mathrm{m} の \mathrm{dead}$ layer が形成されたこ上がわかる，そこで，各段の焼成 後, 粒子を濃硫酸でエッチングを行い, 発光強度之粒子 径の変化を調べた。室温でエッチングした試料 4-4 と $70^{\circ} \mathrm{C}$ でエッチングした試料 4-5 は，標準プロセス 4-1 に比べ発光強度がそれぞれ $4 \%$ と $9 \%$ 增大した。これ は粒度分布が大粒径側に揃ったためであるうと考える。

（4）沈浿を添加した2次焼成

結晶成長を促進する目的で, 1 次粒子と沈激フラック 又の混合物（重量比 $10: 10: 2$ ) 2 次焼成した。この 試料 (4-2) の反射発光強度は。標準プロセスの $45 \%$ 上 著しく低下した.Fig.4の写真をみる上4-2は多くの微 結晶が析出しており，微結晶の析出が 1 次粒子の熟成を 抑制したよ考えられる。この結果から，2次焼成では微 結晶形式を抑制しなけ机ばならないことがわかる。

以上の実験から，2段焼成の結晶成長過程は次の上う に説明できる. 1 次焼成では，初期には核が形成され， その結晶性の良否によって小粒径および至中粒径の粒子 が成長する. 2 次焼成では，不良な結晶から溶質が輸送 されて良質結晶が緩やかに熟成さ机粒子径が均一化さ机 る、したがって.1次焼成では，粒子間で大きな溶質輸 送が行われ，これに対し2次焼成では楥やかな溶質輸送 であり，熱平衡が支配するようになってくる.2 次焼成 後粒成長が停止する原因は，この論法からす㧈は，粒子 径がある程度以上に大きくなる上表面積が小さくなるの で溶質濃度が低下するうえに，成長した大粒径粒子が溶 質の移動を妨げるので一層成長速度が遅められるためで あろうと推定される。粒子の異方性形状はこの段階で大 粒径粒子自身の面や稜が溶解して形成される。

また，酸エッチングは, dead layerを除去することに よって結晶成長を促進する役割を果すが、エッチング上 水洗の処理によって 2 次焼成に有害な微粒子を除去する 効果があるので副次的に発光强度を高める効果もあるの ではないかと考えている。

\section{4 結言}

希土フッ化物を湿式で生成し，フラッタス・多段焼成 法でIRV 蛍光体を合成する実験を行い, 次のことが明 らかになった。

（1）（Y,Yb,Er） $F_{3}$ の緑色発光に関する最適組成 は, $\mathrm{Y}_{0.77} \mathrm{Yb}_{0.20} \mathrm{Er}_{0.03} \mathrm{~F}_{3}$ であり，発光強度は粒子 径に大きく依存する。

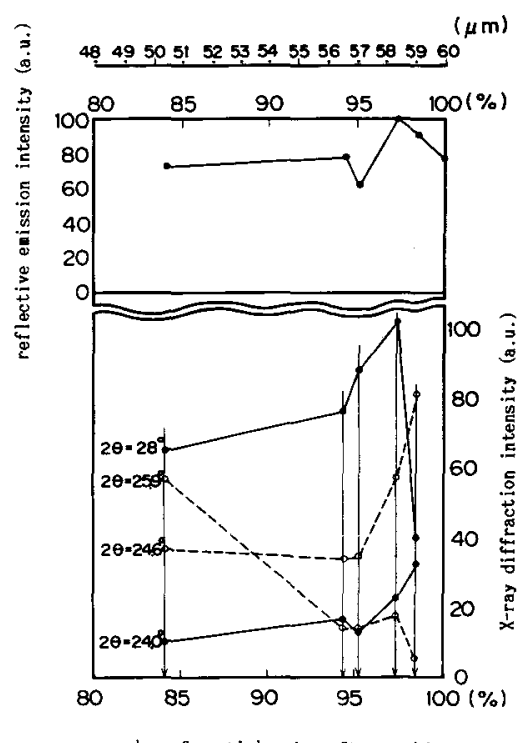

Fig. 5 Effect of etching on reflective emission intensity and $\mathrm{X}$-ray diffraction intensity

(2) $\mathrm{ZnF}_{2} \cdot 4 \mathrm{H}_{2} \mathrm{O}$ フラックスを用いて 2 段焼成を 行い，各段の焼成後に濃硫酸で深いエッチングを 行うことにより，発光効率が高い大粒径粒子が得 ら机た。

（3）大粒径粒子の成長は，2段焼成上酸エッチング の相乗作用による．フラックスの勃果が焼成時間 に対して有限であり，連続焼成よりも2段焼成の 方が発光効率が高い，酸エッチングは，dead layer 除去し，熟成効果を妨げる微粒子を除去 する効果をもつため，2段焼成の効果を高めるこ 上ができる。

以上の上うな合成法の改善によって，光計測に適用可 能な $(\mathrm{Y}, \mathrm{Yb}, \mathrm{Er}) \mathrm{F}_{3}$ の高輝度大粒径粒子を得ることが できた.

\section{文献}

1) 三四 晹, 第 185 回緟光体同学会講演予稿, (1981)

2）鈴木敦，怕田泰利，谷水伸吉，第 175 回営光体同学全 講演予稿, (1979).

3) K. A. Wickershcim and IR. B. Alves, Industrial Res./Dev., Dec. 1979, 82.

4) R. E. Thoma and G. D. Brunton, Inorg. Chem., 5 (11), 1937 (1966).

5) L. G. Van Uitert, L. Piclroski and W. H. Groodkiewicz, Mat. Res. Bull., 4, 777 (1969).

6) 足立吟也，垭川二朗，化学，第 28 卷第 8 号 (1973).

7) 平野正去, 第207回紗光体同学全满演予稿, 23 (1985).

8) J. L. Sommerdjk, J. Luminescence, 6, 61 (1973). 


\section{Abstract}

The synthetic process has been investigated to improve the emission intensity of an infrared-tovisible conversion phosphor. The orthorhombic crystals of $(\mathrm{Y}, \mathrm{Yb}, \mathrm{Er}) \mathrm{F}_{3}$ with the typical size of $60 \mu \mathrm{m}$ were highly yielded by the 2 step-firing using zinc fluoride flux. The best composition for the green emission under infrared (940 and $976 \mathrm{~nm}$ ) excitation was $\mathrm{Y}_{0.77} \mathrm{Yb}_{0.20} \mathrm{Er}_{0.03} \mathrm{~F}_{3}$. The stepwise-firing was very effective for the growth of large crystals, because deteriorated flux was removed. The acid etchings being processed after the firings were also effective for the crystal growth, because excess small particles and nuclei which impede the crystal maturing were removed, and because dead layers on the particle surfaces were removed. 